\title{
A survey of narrative listening behaviors in 8-13-year-old children
}

\author{
Sarah G. Bobbitt ${ }^{1,2}$ Björn Herrmann ${ }^{3,4}$ \& Blake E. Butler ${ }^{2,5-7^{*}}$
}

${ }^{1}$ Graduate Program in Neuroscience, University of Western Ontario, London, Canada ${ }^{2}$ Brain \& Mind Institute, University of Western Ontario, London, Canada

${ }^{3}$ Rotman Research Institute at Baycrest Hospital, Toronto, Canada

${ }^{4}$ Department of Psychology, University of Toronto, Toronto, Canada

${ }^{5}$ Department of Psychology, University of Western Ontario, London, Canada

${ }^{6}$ National Centre for Audiology, University of Western Ontario, London, Canada

${ }^{7}$ Children's Health Research Institute, Lawson Health Research, London, Canada

*Correspondence should be addressed to:

Dr. Blake Butler

The University of Western Ontario

Western Interdisciplinary Research Building 6126

1151 Richmond Street N.

London, Ontario

N6A 5C7 Canada

Phone: 519-661-2111 x 85831

Email: bbutler9@uwo.ca

ORCiD: 0000-0001-5287-3450

Twitter:@BButlerTweets 


\begin{abstract}
Reading confers significant benefits to children in both social and academic domains. However, the number of children who read for pleasure is decreasing and has been recently shown to drop off significantly between the ages of 8 and 9. Despite the rising popularity of audiobooks and podcasts, research on children listening to spoken stories remains in its infancy. Thus, the present study explores how children engage with these novel media. Fifty-two parents of children aged 8-13 years completed an online survey which asked about their children's listening habits. Results showed that $74 \%$ of children listen to spoken stories, with the vast majority (92.5\%) listening at least 1-2 times a week. While the survey revealed children are indeed engaging with both podcasts and audiobooks, being read aloud to continues to be the most popular format for story listening in this age group (77.4\% of listeners). Across platforms, the genre most frequently listened to was fantasy stories (84.9\%; more detailed descriptions of popular themes and sub-themes are described). In sum, access to technology is becoming an increasingly important part of children's lives. The data described here provide a timely perspective and provide a basis for informed studies of listening engagement in children.
\end{abstract}

Keywords: narrative listening, children, podcasts, audiobooks, stories Word Count: 3898 
Running title: NARRATIVE LISTENING IN CHILDREN

\section{Introduction}

The ability to immerse oneself into the world of a story provides an enriching experience that is valued by adults and children alike. In addition to its role as an enjoyable pastime, leisure reading in children has been linked to improved academic performance, reading and spelling ability (Cunningham et al., 2001; Martin-Chang \& Gould, 2008), reading speed (Martin-Chang et al., 2020), and math skills, even after controlling for variables related to socioeconomic status (Sullivan \& Brown, 2015; for a review of leisure reading and its benefits, see Clark \& Rumbold, 2006). However, recent survey data suggest that reading rates among school aged children are in steady decline, with the number of children described as frequent readers (those who read for fun $5+$ days/week) falling by $\sim 1 \%$ per year (Scholastic, 2018). This may, in part, reflect that children's media - like all other media - have changed significantly with the expansion of the internet and the rise of personal devices. The versatility of digital entertainment has enabled the development of platforms that deliver narrated auditory content directed at children, and which may supplement or replace more traditional media (Ipsos, 2020). For example, story-based podcasts and audiobooks developed specifically for children are abundant (Kids Listen, 2021) and in many cases, more accessible than conventional children's media (i.e., print books). However, research about child-directed, spoken narratives is lagging, and the current understanding of how and why children might engage with these narratives remains to be explored.

Developing an understanding of the preferred genres, formats, and listening durations in this age group provide an understanding of how children engage with spoken stories as new listening formats emerge. Moreover, it will enable the design of naturalistic research materials that align with children's preferences, and allow listening behaviors to be studied in the lab using ecologically-valid listening materials. 


\section{Literature Review}

Although podcast use has increased significantly in recent years (Edison, 2021), few systematic studies of how and why adult listeners engage with podcasts have been undertaken (Markman, 2015). In their analysis, Perks and Turner (2019) noted that podcasts, compared to their radio program predecessors, enable greater control over both the content to which one chooses to listen (e.g., which podcast, which episode, for how long) and what else one might choose to do while listening (e.g., commuting, doing chores, relaxing). In addition to this flexibility, a recent survey of college students highlighted three distinct motives for listening to podcasts: entertainment - a desire to enjoy oneself while listening; escapism - a desire to become absorbed in something other than one's own life; and education - a desire to learn new information (Craig et al., 2021). Accordingly, several popular podcasts enjoy large and highly engaged subscriber bases (e.g., Pod Save America), and there are several recent examples of podcasts that have joined "must-see TV" as topics of watercooler conversation (e.g., Serial). As a result, young adults also report social interaction with friends/family and companionship as a significant motive for podcast listening (Chung \& Kim, 2015).

Audiobooks, which pre-date podcasts, have been the subject of a broader body of research. According to the most recent Infinite Dial survey, $46 \%$ of the U.S. population over 12 years old reported listening to an audiobook at least once in their lifetime (Edison, 2021), while a 2019 poll suggested that $20 \%$ of adults had listened to an audiobook in the previous year (Pew, 2019). Like podcasts, audiobooks allow for multitasking, such that individuals are free to spend more time engaging with written materials (Tattersall-Wallin \& Nolin, 2020). For example, many adults listen to audiobooks during commutes, enabling them to engage with stories at a time when print reading may not be possible (Have \& Pederson, 2015). Interestingly, while teenaged 
Running title: NARRATIVE LISTENING IN CHILDREN

boys tend to read less than young women (Brozo et al., 2014), they listen to audiobooks slightly more often than young women, suggesting a smaller gender gap in reading than previously reported, if audiobooks are considered (Tattersall-Wallin \& Nolin, 2020). Thus, across narrative media listening habits and motivations may differ significantly from the habits and motivations surrounding traditional reading. These differences may also exist in children, though to the best of our knowledge this has not yet been investigated.

While podcasts and audiobooks are relatively recent inventions, oral storytelling - in particular telling stories to children - predates the creation of printed books. In the modern context, family members or teachers often read aloud to children, sometimes while the child follows along with the printed text (so-called 'read-along' stories; Cooper, 1993). Interviews with children, including those who ranged from avid to reluctant readers, and their parents suggest that reading aloud to children is an important strategy for encouraging reading for pleasure (McKool, 1998). This finding is supported by a wealth of literature demonstrating that reading aloud to young children improves language development (Debaryshe, 1993), phonemic awareness (Byrne \& FieldingBarnsley, 2001), and storytelling ability and comprehension (NICHD Early Child Care Research Network, 2005). In addition, reading aloud to a child provides an opportunity for rich, engaging interactions (Duursma et al., 2008). This broad array of behavioral benefits is corroborated by brain imaging studies demonstrating that children whose parents regularly engaged in high-quality shared reading time show increased activation in brain regions involved in expressive and complex language, working memory, and social-emotional integration during story listening (Hutton et al., 2017).

Studies of how children engage with audiobooks have largely focussed on their use in educational settings. Audiobooks help encourage and engage reluctant readers by 
Running title: NARRATIVE LISTENING IN CHILDREN

providing a more immersive experience and making it easier for children to engage in stories for longer periods of time without giving up due to lack of reading stamina (James, 2015). Critically, audiobooks also offer a more accessible way for individuals with visual impairments or reading/learning disabilities to engage in stories (Esteves \& Whitten, 2011; Whittingham et al., 2013). Listening to audiobooks thus provides opportunities for the integration of socialization into reading, a tool which may be of particular relevance in elementary education (Whittingham et al., 2013). Additionally, listening to books read aloud can help children learn about pronunciation, fluent reading, and emotional expression (Chen, 2004). Moreover, listening to an audiobook while reading the corresponding text engages students across multiple modalities, providing an enriched experience (Marchetti \& Valente, 2018). Importantly, children listening to audiobooks show similar levels of comprehension compared to children who read the same content, and students report enjoying the text more when listening (Maher, 2019). Hence, audiobooks are a useful tool for encouraging comprehension and making story engagement more accessible. However, it remains unclear how frequently children choose to listen to audiobooks outside of the classroom for their own enjoyment, and what may be their motivations for doing so.

The existing literature on children's use of podcasts and audiobooks focuses on their use in classroom settings, for example, to improve reading ability for students with dyslexia or to encourage reluctant readers (Whittingham et al., 2013; James, 2015). Despite growing interest among children in narrative media for use outside of the classroom, little is known about how children engage with these platforms for enjoyment or entertainment (Moore \& Cahill, 2016). Therefore, in the present study, parents reported on the listening habits of their children via multiple choice and descriptive survey questions that addressed the following research questions: 
RQ1: How frequently do children listen to spoken stories?

RQ2: How long do children normally listen to spoken stories?

RQ3: With which formats do children engage when listening to spoken stories?

RQ4: What genres and qualities of spoken stories do children enjoy most?

\section{Methods}

In order to understand the listening habits of school aged children, 52 parents/guardians of children aged 8-13 years completed an online survey containing both multiple choice and descriptive answer questions. This range was chosen to reflect ages at which reading with a parent has typically transitioned from the sharing of picture books to reading longer works without accompanying imagery (i.e., novels; Hall \& Moats, 2015). Importantly, this range also spans the age at which interest in reading books for fun appears to fall off most severely; only 35\% of 9-year-olds report being frequent readers (reading for fun 5+ days/week) compared to $57 \%$ of 8 -year-olds (Scholastic, 2018).

The survey was administered via Qualtrics (Provo, UT). Recruitment information was circulated via social media, and interested parents/guardians could access the study materials directly using a weblink or QR code. Parents/guardians with more than one child aged 8-13 years were able to provide answers to the survey questions on behalf of each of their children separately. As a result, the survey of 52 parents/guardians provided data from 76 children who were living in Canada or the United States of America. The survey took approximately 5-15 minutes to complete, depending on the level of elaboration a participant chose to provide in written responses, and the number of children for which the participant provided answers. At the end of the survey, participants had the option to provide their email to enter a draw 
Running title: NARRATIVE LISTENING IN CHILDREN

for a chance to win a gift card. All experimental procedures were approved by the University of Western Ontario Non-Medical Research Ethics Board.

In accordance with the goals of this study, survey questions focused on the listening behaviors observed by parents, including the frequency/format/duration of narrative listening, and assessed the content of the stories preferred by children in their care. Given the scarcity of previous research on children's listening preferences, participants were encouraged to provide descriptive summaries of the genres, titles, and story elements their children enjoy most.

The final survey question was open-ended and asked parents to reflect on their child's listening preferences and provide a list of narrative elements that would be most appealing to their child (i.e., "If you could write a story that the child would be interested in listening to, what would you include?"). As expected, this resulted in a broad array of responses that were evaluated and categorized based on content. First, all survey responses were assessed to develop a set of broad content tags that captured the elements included. These tags comprised "comedy", "action", "suspense", "magic/scifi", "animals", and "real life situations". Then, one or more of these content tags were applied to each descriptive response. Finally, responses associated with each content tag were further assessed for the presence of common subthemes (e.g., many participants indicated an interest in "magic", while a subset specified "magical wizards"; Figure 7). The full survey and the data are available at https://osf.io/hnc4f/.

\section{Results}

The 52 parents/guardians surveyed provided data for a total of 76 children between the ages of 8 and 13 years old. No parent elected to withdraw from the survey after accessing the Letter of Information and Consent documentation. Two parents 
began but did not complete the survey, so the data from their 4 combined children were removed prior to analyses. Of the remaining 72 children, $53(74 \%)$ were described as listening to auditory narratives of some type at least once every 2-3 months, with the largest proportions listening either 1-2 times per week (22/72 children [30.6\%]) or daily (27/72 children [37.5\%]; Figure 1). The remaining analyses focused on those children who listen to narratives ( $\mathrm{n}=53$; age breakdown provided in Figure 2). Several of the questions posed to parents/guardians allowed for the selection of one or more responses; as a result, percentages provided may sum to more than $100 \%$.

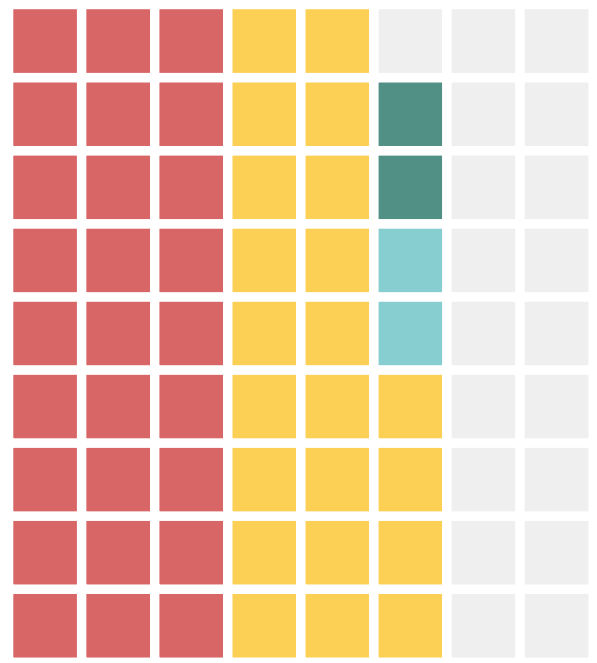

Every day

1-2 times per week

1-2 times per month

Once every 2-3 months Do not listen

Figure 1. Typical frequency of listening for all children. Parents/guardians reported that approximately one quarter of children do not listen to auditory narratives (grey). However, of those children who do listen, a majority do so daily (red). 


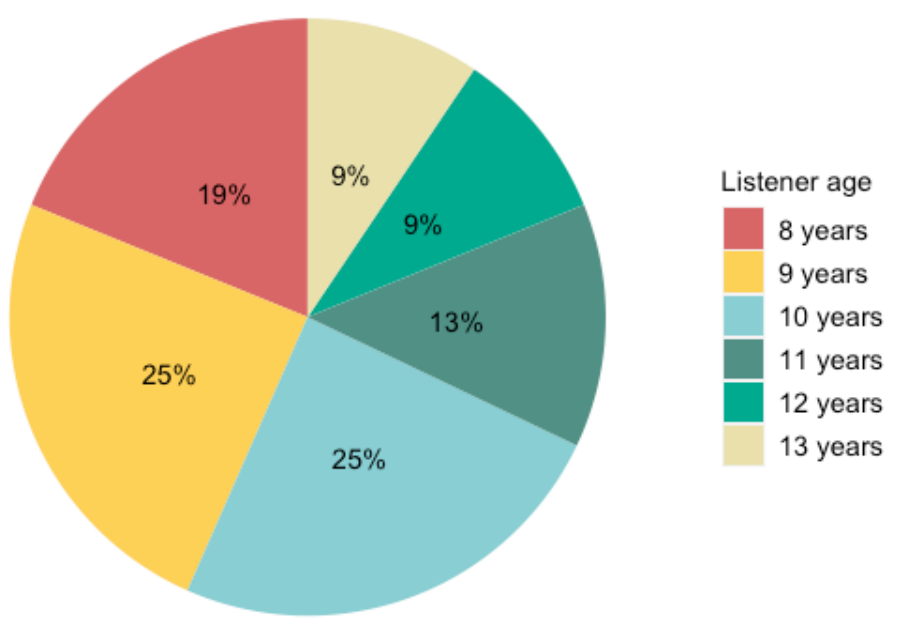

Figure 2. Breakdown of listeners $(\mathrm{n}=53)$ by age.

Of the children who regularly listen to auditory narratives, $21 / 53(39.6 \%)$ were described as listening for twenty or more minutes per session, while only 4/53 (7.5\%) were described as listening for less than 10 minutes at a time (Figure 3). Examining how typical listening duration varies as a function of age (Figure 4), it is clear that the duration of listening increases with a listener's age. About half of children 10 years of age or younger listen to narratives for 15 minutes or less per session, whereas children 11 years of age or older tend to listen for durations in excess of 15 minutes. A KruskalWallis test performed to examine this breakpoint confirmed that children with preferred listening durations of 15 minutes or less were significantly younger $(M=9.21$ years) than those who typically listen for longer durations $(M=10.41$ years; $H(1)=6.39, p=$ $0.012)$. 


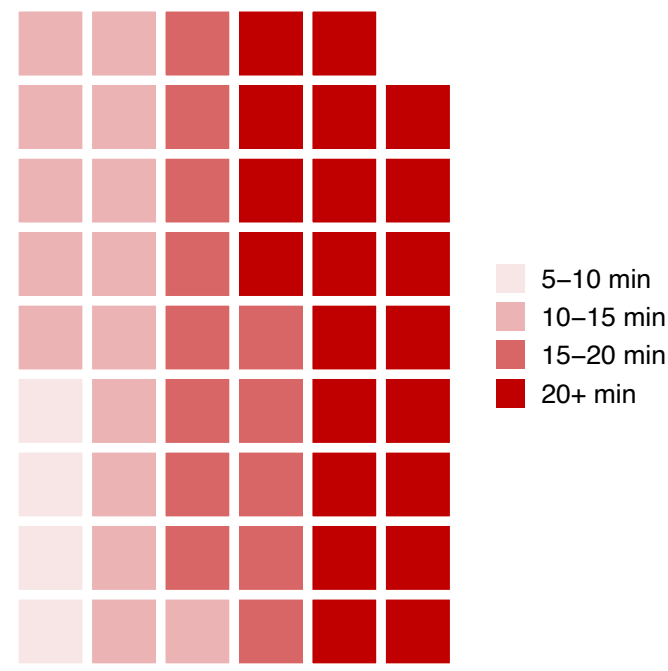

Figure 3. Typical duration of listening for children who do engage with auditory narratives. While some children tend to listen for only brief periods (lighter colors), a large majority of children typically listen for 15 minutes or more per session (darker colors).

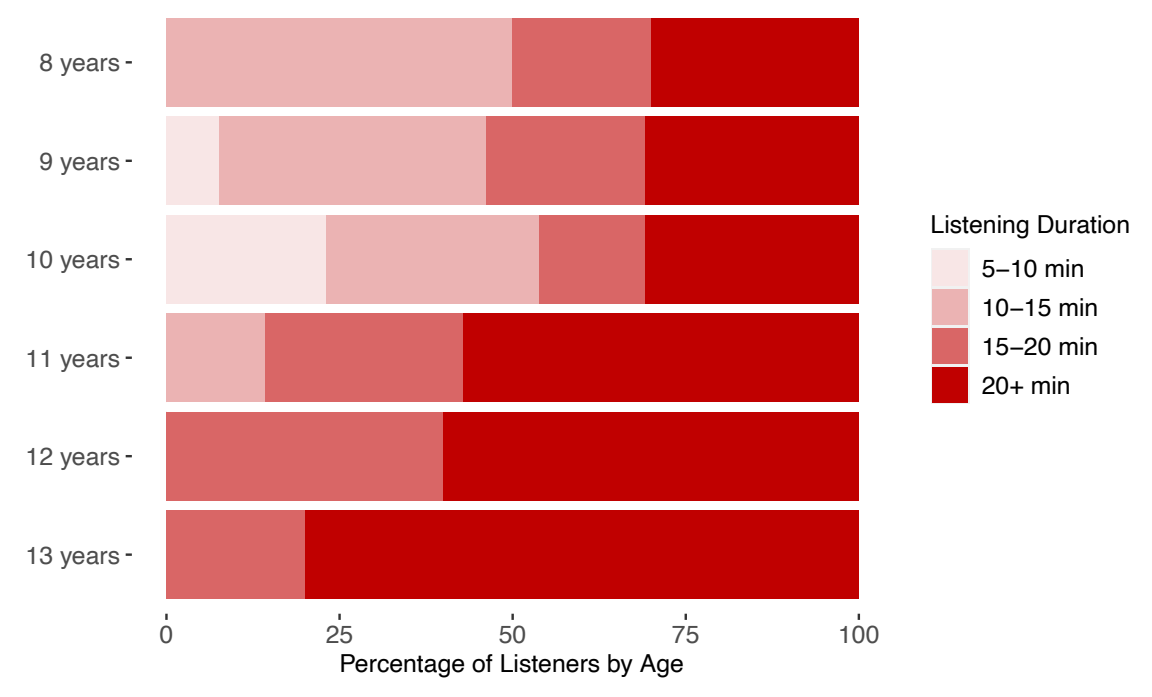

Figure 4. Typical duration of listening as a function of listener age. Note that older children show longer listening durations that younger children as noted by increasingly dark bars with increasing listener age.

When parents/guardians were asked to list all of the means by which their children listen to narratives, the most frequently included response was being read to by someone else (41/53 children [77.4\%]; parents were specifically instructed to consider time spent reading materials without accompanying imagery), followed by podcasts (25/53 children [47.2\%]) and audiobooks (24/53 children [45.3\%]). The least popular 
format was radio (11/53 children [20.8\%]; Figure 5). Notably, for each digital media platform, parents were asked to consider only the time their child spent intentionally listening, to avoid including passive exposures to adult-directed content.

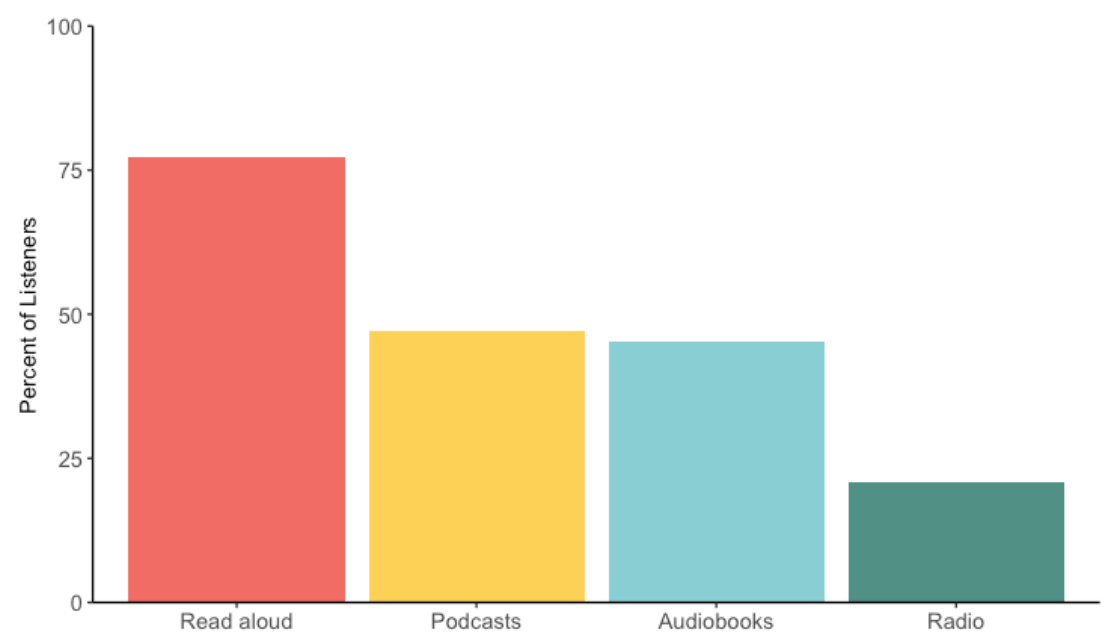

Figure 5. Preferred narrative listening formats. Here, being read aloud to refers specifically to material read without accompanying imagery (i.e., a parent reading to their child from a novel rather than a picture book). More than one-in-four children listen to podcasts and audiobooks.

Parents/guardians were also asked to select all of the narrative genres to which their children listen, and to specify which genre from that selection is their child's favorite (Figure 6). Fantasy stories were most broadly listened to (45/53 children [84.9\%]) and most likely to be described as a child's favourite genre (29/53 children [54.7\%]). Other popular genres included science fiction (listen to: $26 / 53$ children [49.1\%]; favorite: $6 / 53$ children [11.3\%]), realistic fiction (listen to: $25 / 53$ children [47.2\%]; favorite:10/53 children [18.9\%]), and non-fiction or educational content (listen to: $20 / 53$ children [37.7\%]; favorite: $1 / 53$ children [1.9\%]). When asked to elaborate on specific titles or series to which their children most enjoy listening, the responses most often provided by parents/guardians included Harry Potter (14 mentions), Diary of a Wimpy Kid (5 mentions) and Percy Jackson (4 mentions). 


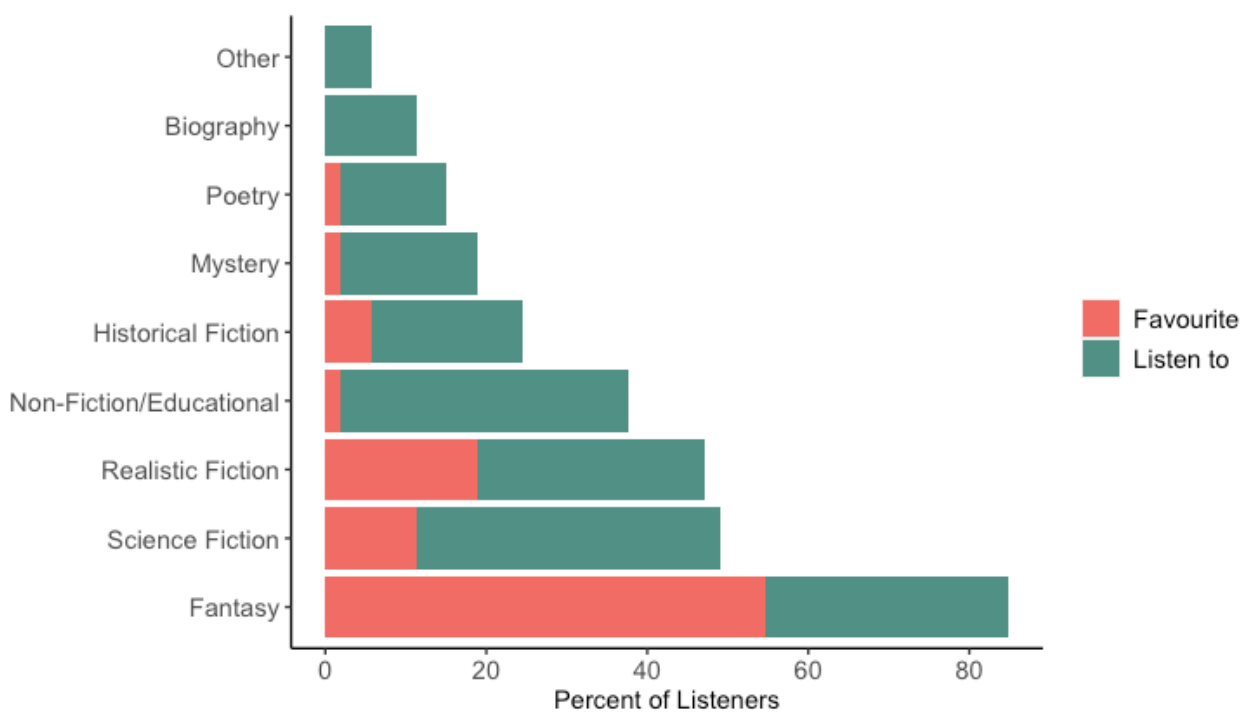

Figure 6. The genres of content to which children listen (light green), and which comprise their favorite (dark green). Note that many parents/guardians reported that their children listen regularly to more than one genre (thus percentages of genres 'listened to' sum to more than 100\%).

Finally, parents/guardians were asked to list the story elements that their children enjoy listening to most, which were aggregated into common themes and subthemes. Forty-one parents chose to complete this written response question, and many provided multiple elements per child. The most frequently included theme was comedy, with $17 / 41$ children [41.5\%] of children enjoying stories with humorous elements (Figure 7). Other prominent themes included action (13/41 children [31.7\%]), suspense (11/41 children [26.8\%]), magic/sci-fi (10/41 children [24.4\%]), real life situations (9/41 children [22\%]), and animals (8/41 children [19.5\%]). The frequencies with which subthemes were reported are provided in Figure 7. Because the question was open ended, some parents commented on engaging elements of auditory narratives that extended beyond thematic content. For example, some responses noted particular sound features their children enjoyed. One parent/guardian wrote that their child "loves when books are being read with great intonation", while another noted that their child "enjoys audiobooks with sound effects". Vocal quality and sound effects were not probed 
explicitly in this study, but narrative elements beyond the content of the story that support listening behavior of children is a topic worthy of further investigation.

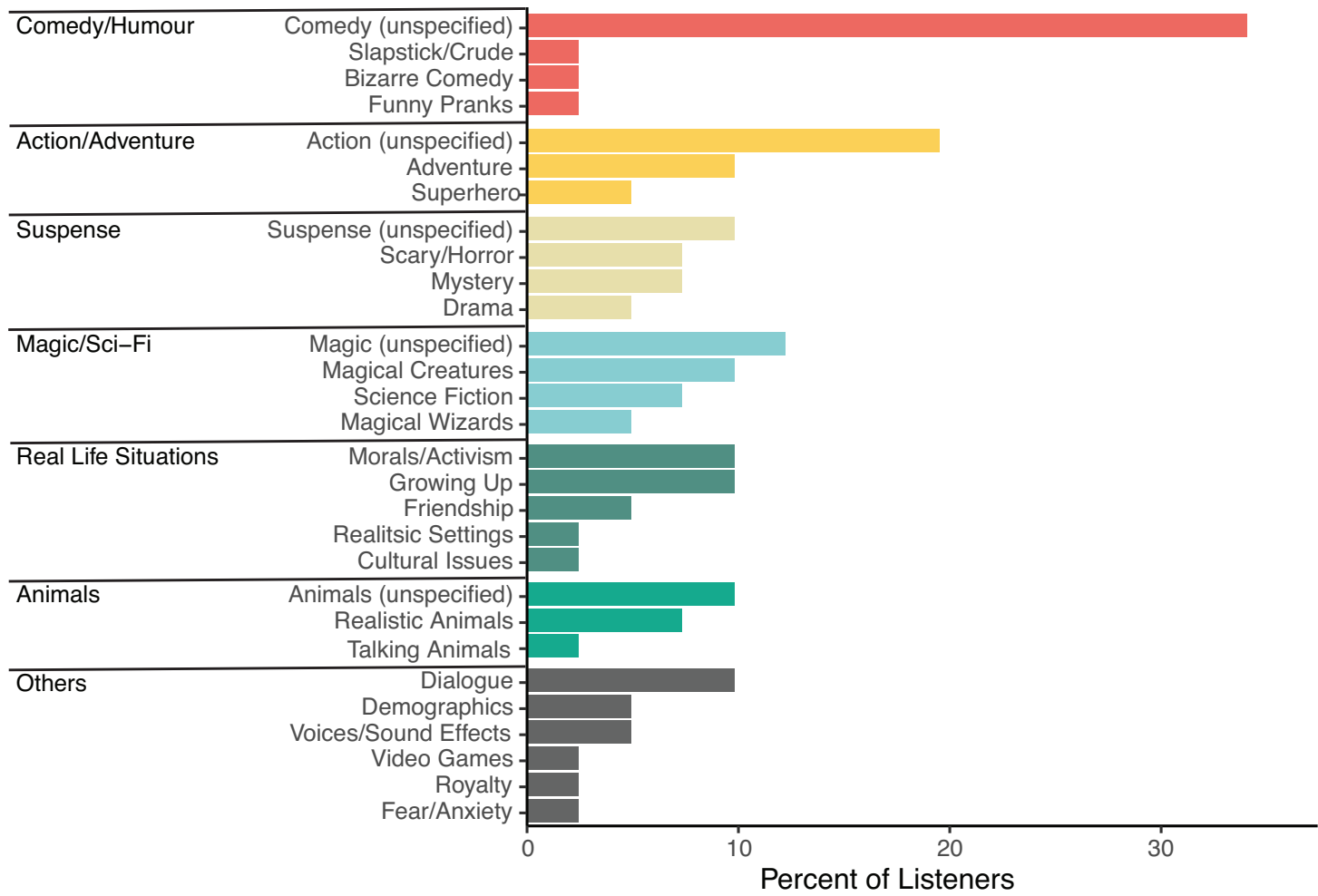

Figure 7. The elements of auditory narratives that parents/guardians suggest most engage their children (note: parents were free to enter multiple themes; thus, totals sum to more than 100\%). Broad categories and more detailed subthemes were drawn from survey responses, and the frequency of each is presented. In each case, 'unspecified' refers to cases in which only the broader theme was identified.

\section{Discussion}

\section{Quantifying narrative listening}

The rise of digital media and unparalleled access to online resources has led to a dramatic increase in the use of auditory narratives, including among children (Ipsos, 2020). Despite this, very little is known about how children are engaging with these resources. The current report provides detailed information regarding the way children aged 8-13 listen to spoken narratives. 
Running title: NARRATIVE LISTENING IN CHILDREN

Fifty-three of the children for whom data were provided (74\%) were described as listening to spoken narrative at least occasionally (at least once every 2-3 months), while the remainder do not appear to engage with these materials. With respect to the frequency of narrative listening, a large majority of children who listen to stories do so at least once per week (49/53 children [92.5\%]) while only a very small number of children are "casual" listeners (Figure 2). Being read aloud to was the most popular way in which children aged 8-13 engage with auditory narratives (41/53 children [77.4\%]). These data illustrate that spoken story listening in children often occurs with another person, which may help facilitate the enriching parent-child interactions described by Duursma and colleagues (2008). These parent-child story listening experiences underscore that socializing with friends/family can be a significant motivator for spoken story listening in young adults (Chung \& Kim 2015).

The current study further shows that a significant proportion of children also utilize newer media, including podcasts and/or audiobooks (25/53 children [47.2\%] and $24 / 53$ children [45.3\%], respectively), to listen to auditory narratives. However, we did not capture how often children engage in podcast/audiobook listening with a parent/guardian or with other children. Regardless, it is clear from the data presented here that children are actively engaging with emerging digital story telling platforms that have been shown to provide highly individualized listening experiences over which the child may have more control when compared to traditional print media (TattersallWallin \& Nolin, 2020).

\section{Popular and preferred narrative genres}

In addition to exploring the ways children listen to spoken stories, this survey also describes the qualities of listening experiences that children enjoy the most. When 
Running title: NARRATIVE LISTENING IN CHILDREN

comparing how many children listen to a genre and how often that each genre was perceived to be the child's favorite, there is better correspondence for some genres than for others. Fantasy stories were reported as both the most listened to genre, and the genre most frequently listed as a child's favorite. Science fiction and realistic fiction were the next most frequently listened to genres and were also highly likely to be rated as a child's favorite genre, although there was a preference for realistic fiction $(10 / 53$ children [18.9\%]) over science fiction (6/53 children [11.3\%]; Figure 6). However, parents also reported that their children commonly listen to some genres that were very unlikely to be described as a child's favorite. Non-fiction/educational stories, for example, are listened to by $20 / 53$ children (37.7\%), but are listed as the favorite of only $1 / 53$ children $(1.9 \%)$. It is unclear from where these popularity/preference distinctions arise. In the case of educational narratives, for example, it is possible that the rate of listening may be inflated by an observation bias, wherein parents are inclined to report a genre that would be favorably evaluated by the experimenter, or that parents are using these tools to support early education despite their child's preference for other genres. It is also possible that, as the use of digital platforms like podcasting take on an increased role in formal instruction (Goldman, 2018), children's exposure to these media may include a significant portion of assigned listening. Further research should investigate potential differences in the types of stories children are engaging in across different settings (e.g., in school vs. at home) and levels of autonomy (e.g., stories listened to by choice vs. chosen by a parent or teacher).

Children's genre preferences were echoed in the specific story/podcast titles mentioned by parents. Four of the top six most frequently mentioned titles were fantasy/adventure novels, while the remaining two are humorous realistic fiction. Interestingly, while it was reported that a significant number of children in the sample 
Running title: NARRATIVE LISTENING IN CHILDREN

listen to podcasts, only a small number of the specific titles listed by parents $(\sim 22 \%)$ were podcast titles. One likely explanation is that parents/guardians are less aware of which podcasts their children are listening to, perhaps because children are listening to them on their own and are able to acquire them without the help of the parent (podcasts are typically free, and accessible through a variety of mobile apps). Future studies may wish to ask children directly which podcasts they listen to or ask parents to seek out this information explicitly in order to gain a better understanding of podcast preferences in children.

\section{The role of humor in narrative listening}

When narrative listening preferences were explored in detail, the most frequently mentioned theme was humor, with parents/guardians reporting that more than $40 \%$ of children enjoy comedic stories. Few parents elaborated on the types of comedic elements their children enjoyed. However, where specific information was provided, parents suggested that their children enjoyed stories that featured slapstick or crude humor, bizarre humor, or comedic pranks (Figure 7). While humor is not typically included amongst traditional lists of literary genres (Clark \& Foster, 2005), it may represent an important element, specifically in child-directed media. For example, literary humor has been proposed to alleviate childhood anxieties, worries, and fears and in doing so, has been suggested to be an important support for well-being (Xeni, 2010). Moreover, learning to engage appropriately with humor can provide significant prosocial benefits throughout development, and may provide a lifelong resource for responding to both everyday challenges and traumatic events (see Bergen 2021 for review). It would be interesting to examine which humorous elements drive engagement with auditory narratives in more detail, and to assess the extent to which podcasts and 
Running title: NARRATIVE LISTENING IN CHILDREN

audiobooks engage humor to deal with circumstances that might otherwise give rise to anxiety or fear.

\section{Limitations}

The current study focused on gaining a broad picture of how children are engaging with spoken narrative materials across formats. As such, the sampling frame was not restricted (except that study documentation was only provided in English) and the study was designed for remote delivery to remove potential geographic barriers. However, we did not collect information about the sex/gender, race/ethnicity, or socioeconomic status of our survey respondents or the children in their care, and thus cannot make any inference about the role these factors may play in story listening behaviours. In future, a more fulsome consideration of how individual differences in story listening may relate to these demographic dimensions may be informative.

It was reported that a plurality of children (21/53 children [39.6\%]) in the current study commonly listen for twenty minutes or more at a time, whereas only $4 / 53$ children $(7.5 \%)$ were described as listening for five to ten minutes on average per session (Figure 3). However, these listening durations are substantially shorter than the average listening durations of adults reported by Tattersall-Wallin and Nolin (2020), who found that young adults aged 18 to 20 years listen to audiobooks for ninety to one hundred minutes per day. Although the longest duration presented as an option in the current survey may have included respondents who listen considerably longer than twenty minutes per session, this discrepancy in length between children and adults mirrors that observed for other media types (Nielsen, 2016; American Academy of Child \& Adolescent Psychiatry, 2020). Indeed, children's media such as books and television shows tend to be shorter in length than similar media intended for adults 
Running title: NARRATIVE LISTENING IN CHILDREN

(Writer's Relief, 2009). Nevertheless, future research may consider more fine-grained options for listening durations exceeding twenty minutes.

\section{Conclusions}

The media landscape is rapidly evolving and the availability of podcast/audiobook platforms as entertainment and educational media for children is expanding. The current study comprises a critical step in understanding how children engage with emerging narrative formats. Specifically, we explored how children aged 8-13 years engage with spoken stories, investigating the duration, format, and frequency of story listening as well as the qualities of spoken stories that children enjoy most. Reading aloud with an adult remains very popular. However, nearly half of the children who listen to narrative materials do so via podcasts and/or audiobooks. As reading for pleasure is known to decline across this age range, developing a more complete understanding of how children engage with these emerging formats may be critical to supporting continued engagement with written materials.

\section{Funding Details}

This research was funded by strategic support from the University of Western Ontario awarded to BEB (Grant \# R5571A09). BH was supported by the Canada Research Chair program.

\section{Disclosure Statement}

The authors report there are no competing interests to declare.

\section{Data Availability Statement}

The survey and data described here can be found at https://osf.io/hnc4f/. 
Running title: NARRATIVE LISTENING IN CHILDREN

\section{References}

American Academy of Child and Adolescent Psychiatry. (2020). Facts for Families: Screen Time and Children.

https://www.aacap.org/AACAP/Families_and_Youth/Facts_for_Families/FFFGuide/Children-And-Watching-TV-054.aspx

Bergen, D. (2021). Humour as a resource for children. In The Palgrave Handbook of Humour Research (pp. 311-323). Springer.

Brozo, W.G., Sulkunen, S., Shiel, G., Garbe, A.P., \& Valtin, R. (2014). Reading, gender, and engagement: Lessons from five PISA countries. Journal of Adolescent \& Adult Literacy, 57(7), 584-593. https://doi.org/10.1002/jaal.291

Byrne, B., \& Fielding-Barnsley, R. (1991). Evaluation of a program to teach phonemic awareness to young children. Journal of Educational Psychology, 83(4), 451-455. https://doi.org/10.1037/0022-0663.83.4.451

Chen, S.-H. L. (2004). Improving Reading Skills through Audiobooks. School Library Media Activities Monthly, 21(1), 22-25.

Chung, M.-Y., \& Kim, H.-S. (2016). College Students' Motivations for Using Podcasts. Journal of Media Literacy Education, 7(3), 13-28.

Clark, C., \& Rumbold, K. (2006). Reading for Pleasure: A Research Overview. In National Literacy Trust. National Literacy Trust. https://eric.ed.gov/?id=ED496343

Cooper, J.D. (1993). Literacy: Helping children construct meaning ( $2^{\text {nd }}$ ed.). Boston: Houghton Mifflin Company.

Craig, C. M., Brooks, M. E., \& Bichard, S. (2021). Podcasting on purpose: Exploring motivations for podcast use among young adults. International Journal of Listening, 1-10. https://doi.org/10.1080/10904018.2021.1913063 
Cunningham, A. E., Perry, K. E., \& Stanovich, K. E. (n.d.). Converging evidence for the concept of orthographic processing. 20.

Debaryshe, B. D. (1993). Joint picture-book reading correlates of early oral language skill. Journal of Child Language, 20(2), 455-461. https://doi.org/10.1017/S0305000900008370

Duursma, E., Augustyn, M., \& Zuckerman, B. (2008). Reading aloud to children: The evidence. Archives of Disease in Childhood, 93(7), 554-557. https://doi.org/10.1136/adc.2006.106336

Edison Research (2021). The Infinite Dial 2021 [PowerPoint slides]. http://www.edisonresearch.com/wp-content/uploads/2021/03/The-Infinite-Dial2021.pdf

Esteves, K., \& Whitten, E. (2011). Assisted Reading with Digital Audiobooks for Students with Reading Disabilities. Reading Horizons, 51(1), 21-40.

Goldman, T. (2018). The Impact of Podcasts in Education. Advanced Writing: Pop Culture Intersections. 29.

Hall, S., \& Moats, L. (2015). Why Reading to Children is Important. In Literacy Ladders: Increasing Young Children's Language, Knowledge, and Reading Comprehension (pp. 22-29).. Albert Shanker Institute.

Have, I., \& Pedersen, B. S. (2015). Digital Audiobooks: New Media, Users, and Experiences. Routledge. https://doi.org/10.4324/9781315743080

Hutton, J. S., Phelan, K., Horowitz-Kraus, T., Dudley, J., Altaye, M., DeWitt, T., \& Holland, S. K. (2017). Shared Reading Quality and Brain Activation during Story Listening in Preschool-Age Children. The Journal of Pediatrics, 191, 204-211.e1. https://doi.org/10.1016/j.jpeds.2017.08.037 
Ipsos. (2020). Ipsos Kids and Family Study. https://www.ipsos.com/enca/knowledge/media-brand-communication/Audio-in-the-Lockdown-HouseholdThe-Emergence-of-Podcasts-Among-Kids-Families

James, C. C. (2015). Engaging Reluctant Readers through Audiobook Project. 2, 23.

Kids Listen. (2021). All Kids Listen Podcasts. https://app.kidslisten.org/podcasts

Maher, C. (2019). Enhancing literacy skills using audiobooks: Comprehension and enjoyment of text in the second grade classroom [Master's thesis|]. http://www.theseus.fi/handle/10024/185940

Marchetti, E., \& Valente, A. (2018). Interactivity and multimodality in language learning: The untapped potential of audiobooks. Universal Access in the Information Society, 17(2), 257-274. https://doi.org/10.1007/s10209-017-0549-5

Markman, K. M. (2015). Considerations-Reflections and Future Research. Everything Old is New Again: Podcasting as Radio's Revival. Journal of Radio \& Audio Media, 22(2), 240-243. https://doi.org/10.1080/19376529.2015.1083376

Martin-Chang, S., Kozak, S., \& Rossi, M. (2020). Time to read Young Adult fiction: Print exposure and linguistic correlates in adolescents. Reading and Writing, 33(3), 741760. https://doi.org/10.1007/s11145-019-09987-y

Martin-Chang, S. L., \& Gould, O. N. (2008). Revisiting print exposure: Exploring differential links to vocabulary, comprehension and reading rate. Journal of Research in Reading, 31(3), 273-284. https://doi.org/10.1111/j.1467$\underline{9817.2008 .00371 . x}$

McKool, S. S. (n.d.). Factors that influence the decision to read: An investigation of fifth grade students' out-of-school reading habits [Ph.D., The University of Texas at Austin]. Retrieved August 31, 2021, from https://www.proquest.com/docview/304458103/abstract/B3BB2D307BC148E3PQ/1 
Running title: NARRATIVE LISTENING IN CHILDREN

Moore, J., \& Cahill, M. (2016). Audiobooks: Legitimate "Reading" Material for Adolescents? School Library Research, 19. https://eric.ed.gov/?id=EJ1120838

NICHD Early Child Care Research Network. (2005). Pathways to Reading: The Role of Oral Language in the Transition to Reading. Developmental Psychology, 41(2), 428442. https://doi.org/10.1037/0012-1649.41.2.428

Nielsen. (2016). The Total Audience Report: Q1 2016. https://www.nielsen.com/us/en/insights/report/2016/the-total-audience-report-q1$2016 /$

Perks, L. G., \& Turner, J. S. (2019). Podcasts and Productivity: A Qualitative Uses and Gratifications Study. Mass Communication and Society, 22(1), 96-116. https://doi.org/10.1080/15205436.2018.1490434

Pew Research Center. (2019). One-in-five Americans now listen to audiobooks. https://www.pewresearch.org/fact-tank/2019/09/25/one-in-five-americans-nowlisten-to-audiobooks/

Scholastic (2018). Kids and Family Reading Report - 7th Edition. https://www.scholastic.com/readingreport/navigate-the-world.html

Sullivan, A., \& Brown, M. (2015). Reading for pleasure and progress in vocabulary and mathematics. British Educational Research Journal, 41(6), 971-991. $\underline{\text { https://doi.org/10.1002/berj.3180 }}$

Summers, K. (2013). Adult Reading Habits and Preferences in Relation to Gender Differences. Reference \& User Services Quarterly, 52(3), 243-249. https://doi.org/10.5860/rusq.52.3.3319

Tattersall-Wallin, E., \& Nolin, J. (2020). Time to read: Exploring the timespaces of subscription-based audiobooks. New Media \& Society, 22(3), 470-488. https://doi.org/10.1177/1461444819864691 
Running title: NARRATIVE LISTENING IN CHILDREN

Whittingham, J., Huffman, S., Christensen, R., \& McAllister, T. (2013). Use of Audiobooks in a School Library and Positive Effects of Struggling Readers' Participation in a Library-Sponsored Audiobook Club. School Library Research, 16. https://eric.ed.gov/?id=EJ1012831

Writer's Relief. (2009). Genre fiction rules: Find out if your novel meets publishers' and literary agents' criteria for publication. https://writersrelief.com/2009/06/18/genrefiction-rules-find-out-if-your-novel-meets-publishers-and-literary-agents-criteria-forpublication/

Xeni, E. (2010). Meeting childhood needs: The need for humour in children's literature. In: Negotiating Childhoods (pp. 151-160). Brill. 